\title{
Chemical control of Root-Knot Nematode (Meloidogyne javanica) On Olive in the Greenhouse conditions
}

\author{
Tahereh Soltani ${ }^{1 *}$, Reza Farokhi Nejad ${ }^{1}$, Ali Reza Ahmadi ${ }^{2}$ and Fatemeh Fayazi ${ }^{1}$ \\ ${ }^{1}$ Department of Plant Protection, College of Agriculture, Shahid Chamran University, Ahvaz, Iran \\ ${ }^{2}$ Department of Plant Protection, Agriculture and Natural Resources Research Centre of Khuzestan, Ahvaz, Iran
}

\begin{abstract}
Root knot nematodes of Meloidogyne spp. are among the most damaging plant pathogens worldwide. Meloidogyne Species Known of this genus which damage olive trees are sporadically found in wild olives, olive nurseries and established orchards; they generate gall on the roots and delay plant growth. In this study, the impact of nematicide toxins of Aldicarb, Enzon, Oxamyl, and Cadusafos with concentrations of 6 and 8 ppm on olive's root knot nematode in one-year old olive seedlings, collected from Dezfoul, was studied in a greenhouse. The results of this study showed that Rugby toxin with concentration of 8 ppm (79/24 percent reduction in nematode population) and Enzone toxin with concentration of $8 \mathrm{ppm}$ (50/38 percent reduction in nematode population) had, respectively, the most and least effect in the control of nematode. This experiment was done by inoculation of 5000 eggs and second instar larvae in a completely randomized design with three replications.
\end{abstract}

Keywords: Meloidogyne javanica; Nematode; Olive; Concentration

\section{Introduction}

Olive, whose scientific name is Olea europea L., is a plant from Oleaceae family and Olea genus [1]. Olive is among the trees that have multiple benefits and nearly all of its parts are used. Its main products are oil and conserve [1]. According to the statistics provided by Food and Agriculture Organization of United Nations (FAO) in 2009 A. D., olive cultivation in Iran has been 31,114 hectares and the rate of the product 40,025 ton [2]. Cultivation of aqueous olive in the Khuzestan province, in 1387 has been $4789 / 79$ hectares and its product, in the same year, 606230/30 kilogram per hectare whose product yielded 1442/52 kilogram per hectare [3]. More than 100 species belonging to 47 genera have been reported from plant parasitic nematodes associated with olive [4]. Among the nematodes, the root-knot nematodes of $M$. arenaria, M. incognita, M. javanica are of great importance [5]. Also, according to Nicol et al. [6], species of $M$. arenaria, $M$. incognita, $M$. javanica, $M$. lusitanica possess the highest potential to damage olive cuttings in the orchards of Indonesia and South of Spain. Barouti and Holami [7] reported the nematodes of M. javanica, Tylenchulus semipenetrans and Xiphinema pachtaicum from olive orchards of Gilan for the first time. Hoseininejad et al. [8] separated 26 species and 19 genera of nematodes from olive trees by which dominant genera of olive parasite nematode, $M$. javanica, and two species of Helicotylenchus were identified. Mahdikhani Moghaddam et al. [9] collected the rootknot nematode called M. cruciani from Rudbar's roots of olive.

Nematodes management in ideal agricultural systems can be achieved by combining different tactics like preventing nematode's entrance, using resistant varieties, and chemical and biological controlling. In Integrated Pest Management (IPM), using nematicides can be combined with other control tactics by the purpose of the use of low doses of toxin [4]. All nematicides were effective in reducing the number of nematodes both in the soil and on the roots. But Fenamiphos made the greatest reduction in the number of nematodes in the soil and the number of galls, females and egg masses while Carbofuran caused the lowest rate of reduction in this sense [10]. Hoseininejad [11] showed that Temik toxin has possessed the best effect in controlling nematodes and Oxamyl, Rugby, and Mucap, respectively, were in the next categories. Rostami et al. [12] reported that treatment of Vapam has encompassed the highest impact on controlling the nematodes.

The traditional methods used to protect crops from diseases, mostly, have been based on the use of chemicals. The use of fungicides and fumigatory nematicides can have devastating effects on the environment and consumer and are often used in agriculture more than herbicides and pesticides. Chemical methods are not economical in the long run because, in addition to polluting the air, soil, and environment, they can result in developing resistant strains in the organism of the objective by frequent uses [13].

This experiment was conducted regarding the Fifth Development Plan, suggesting that olive cultivation in the province, Khouzestan, is developing and according to reports of the researchers of Research Center for Agriculture and Natural Resources of the province announcing that 75 percent of greenhouses and seedling production centers of the province have been infested and polluted by the root-knot olive nematode and that the infected plants, due to production costs, must somehow be disinfected and free of nematodes. Also, due to the difficulties of using granular pesticides by farmers, three liquid toxins which are easier to use by farmers were applied in this study.

\section{Materials and Methods}

\section{Nematodes' Sampling, Extracting, and Reproducing in Greenhouse Experiments}

Sampling was done from the surrounding roots and soil of olive and also olive orchards and greenhouses in some towns of Khouzestan like Bagh Malek, Shoush, Ramhormoz, and Dezfoul. The samples were

${ }^{*}$ Corresponding author: Tahereh Soltani, Department of Plant Protection College of Agriculture, Shahid Chamran University, Ahvaz, Iran, E-mail: vTah_id_120@yahoo.com

Received May 23, 2013; Accepted June 19, 2013; Published June 24, 2013

Citation: Soltani T, Nejad RF, Ahmadi AR, Fayazi F (2013) Chemical control of Root-Knot Nematode (Meloidogyne javanica) On Olive in the Greenhouse conditions. J Plant Pathol Microb 4: 183 doi:10.4172/2157-7471.1000183

Copyright: ( $\odot 2013$ Soltani T, et al. This is an open-access article distributed unde the terms of the Creative Commons Attribution License, which permits unrestricted use, distribution, and reproduction in any medium, provided the original author and source are credited. 
placed in plastic bags and transported to the laboratory with the name, location, and date of collection. For this purpose, first, nematode-infected roots of the olives were gently washed with water and cut into pieces of 2 to 3 centimeters. Then, below binocular using sharp and arrowhead needle, egg masses were carefully removed and placed in distilled water. After that, disinfection was done by placing the removed egg masses in commercial vaytks (10\%) for four minutes. For reproducing nematode, first, tomato (Lycopersicon esculentum Mill. (cv. Rutgers was implanted in pots with diameter of 12 centimeters containing sterilized soil with a 1:1:1 ratio (soil, sand, leaf compost) in the greenhouse of the faculty of Shahid Chamran University. After the seedlings reached to the stage of having 3 to 4 leaves, a 1/5-2 centimeters deep pit was created near the seedlings and then one disinfected egg mass was placed in each pot and the pots were irrigated when needed. After 2-3 months, plants were taken from the soil and symptoms of nematode infection were observed in the roots. Extraction of nematode egg and second instar larvae of the tomato plants were removed from pots and the roots were washed with water and cut into smaller parts. Five grams of roots were placed in the box of an electric mixer. By adding $100 \mathrm{ml}$ of water and $500 \mathrm{ml}$ of $1 \%$ sodium hypochlorite solution at high speed of the mixer for about 40 seconds, the roots were completely crushed and the eggs released. After this stage, materials inside the mixer were passed through two sieves of 100 and 400 meshes and the content of 400 meshes sieve were collected within a beaker after being washed several times with distilled water. Then these materials were transferred into centrifuge tubes and after two stages of centrifuge, the eggs were collected [14].

\section{The impact of nematicides on plive seedlings in the green-} house

For this experiment, three liquid nematicides of Enzone (403 gr/l), Cadusafos (Rugby) (1200 gr/l), and Oxamyl (Vydate) (240 gr/l) and granule nematicide of Aldicarb (Temik, $10 \mathrm{G}$ ) were used. First, oneyear old olive seedlings, Dezfoul figure, obtained from a greenhouse free of nematode infection in Khouzestan, were implanted in pots with diameter of 18 centimeters containing disinfected soil with a 1:1:1 ratio (soil, sand, leaf composts) in the greenhouse. To inoculate the nematode, first, few holes were established around the seedlings' roots. Then, the number of intended nematodes was added to the foot of the seedlings by using pipette; to inoculate the liquid toxins, a hole was also created at the foot of the seedlings and then the intended toxin was poured there. Meanwhile, to inoculate Temik toxin used in a granule way, after creating a hole at the foot of the seedlings, the toxin was poured into the hole and then the soil taken from the foot of the bushes was slowly placed on the toxin. This experiment carried out with 10 treatments and 3 repetitions in a completely randomized design with the following treatments:

\section{Control (without nematode)}

2. Control (Plant inoculation with 5000 eggs and second instar larvae) and without toxin

3. Adding Vaydate toxin with concentration of $6 \mathrm{ppm}$ a week after inoculation of plant with 5000 eggs and second instar larvae of nematode

4. Adding Vaydate toxin with concentration of $8 \mathrm{ppm}$ a week after inoculation of plant with 5000 eggs and second instar larvae of nematode

5. Adding Enzone toxin with concentration of $6 \mathrm{ppm}$ a week after inoculation of plant with 5000 eggs and second instar larvae of nematode
6. Adding Enzone toxin with concentration of $8 \mathrm{ppm}$ a week after inoculation of plant with 5000 eggs and second instar larvae of nematode

7. Adding Rugby toxin with concentration of $6 \mathrm{ppm}$ a week after inoculation of plant with 5000 eggs and second instar larvae of nematode

8. Adding Rugby toxin with concentration of $8 \mathrm{ppm}$ a week after inoculation of plant with 5000 eggs and second instar larvae of nematode

9. Adding Temik toxin with concentration of 6 ppm and 5000 eggs and second instar larvae of nematode simultaneously

10. Adding Temik toxin with concentration of 8 ppm and 5000 eggs and second instar larvae of nematode simultaneously

The pots were kept and irrigated when required in the greenhouse of Agricultural Research Center for 6 months at a constant temperature of $25 \pm 2^{\circ} \mathrm{C}$. After this period, the seedlings were removed from the soil and after cutting the shoots, the roots of each pot were separately washed and weighed; and the number of egg mass and its index, population of egg and second instar larvae of the soil and vase was extracted and counted using Jenkinz method [15]. Gall level was assessed based on gall index.

\section{Assessment of pesticides}

To evaluate the effect of toxins, percent reduction of nematode's population for each treatment was counted by comparing the initial population of nematode with final population according to the following formula:

Percent reduction of nematode's population $\frac{\text { initial population-final population }}{\text { initial population }} \times 100$

\section{Results and Discussion}

Aldicarb toxin with the commercial name of Temik in the form of granule, Cadusafos toxins with the commercial names of Rugby and Traden, Oxamyl under the name of Vydate, and Enzone toxin in liquid form were used in the study.

According to the table of variance analysis of eggs and second instar larvae of nematode in the soil, there is a significant difference between the treatments in the one percent level but the number of eggs and larvae of nematode in the roots of all experimented treatments was statistically identical (Table 1). Comparing the mean of the data with Duncan test put the treatments into two groups A and B (Table 2). The results showed that Rugby toxin with concentration of $8 \mathrm{ppm}$ had the best effect in controlling the root-knot nematode of $M$. javanica (with

\begin{tabular}{|c|c|c|c|c|}
\hline \multirow{2}{*}{$\begin{array}{l}\text { changes } \\
\text { Sources }\end{array}$} & \multirow{2}{*}{$\begin{array}{l}\text { Degrees of } \\
\text { freedom }\end{array}$} & \multicolumn{3}{|l|}{ MS } \\
\hline & & $\begin{array}{l}\text { The total of } \\
\text { population }\end{array}$ & $\begin{array}{l}\text { Number of eggs and } \\
\text { larvae in the soil }\end{array}$ & $\begin{array}{l}\text { Number of eggs } \\
\text { and larvae of the } \\
\text { root }\end{array}$ \\
\hline Treatment & 9 & 109.51 & 58.88 & 57.03 \\
\hline Error & 20 & 27.62 & 9.55 & 34.61 \\
\hline Total & 29 & - & - & - \\
\hline C.V & - & $32.20 \%$ & $25.25 \%$ & $57.34 \%$ \\
\hline F-value & - & $3.97^{* *}$ & $6.17^{* *}$ & 1.65(n.s) \\
\hline
\end{tabular}

** : Treatments are significant at the $1 \%$ level.

n.s: non significant

Table 1: Variance analysis of the nematocide effects testing on control of Meloidogyne javanica on olive trees cv Dezfuli. 
Citation: Soltani T, Nejad RF, Ahmadi AR, Fayazi F (2013) Chemical control of Root-Knot Nematode (Meloidogyne javanica) On Olive in the Greenhouse conditions. J Plant Pathol Microb 4: 183 doi:10.4172/2157-7471.1000183

Page 3 of 4

\begin{tabular}{|c|c|c|c|c|c|c|}
\hline Treatment & Root weight & $\begin{array}{l}\text { Number gal/Gall } \\
\text { index }\end{array}$ & $\begin{array}{l}\text { Population of root } \\
\text { eggs and larvae }\end{array}$ & $\begin{array}{l}\text { Number of eggs and } \\
\text { larvae in the soil total }\end{array}$ & $\begin{array}{l}\text { Reproduction } \\
\text { factor }\end{array}$ & $\begin{array}{l}\text { reduction Percent in } \\
\text { nematode population }\end{array}$ \\
\hline $\begin{array}{l}\text { Control without nematode and } \\
\text { toxin }\end{array}$ & 40 & 0 & 0 & B 0 & 0 & - \\
\hline $\begin{array}{l}\text { Control nematode and without } \\
\text { toxin }\end{array}$ & 31 & $1(1)$ & 730 & A 8167 & 1.68 & - \\
\hline Temik ppm 6 & 32 & $1(1)$ & 167 & A 1424 & 0.32 & 68.18 \\
\hline Temik ppm 8 & 30 & $1(1)$ & 50 & A 1336 & 0.28 & 72.28 \\
\hline Oxamyle ppm 6 & 29 & $1(1)$ & 133 & A 1600 & 0.38 & 70.66 \\
\hline Oxamyle ppm 8 & 33 & $1(1)$ & 117 & A 1552 & 0.33 & 66.64 \\
\hline Rugby ppm 6 & 33 & $2(1)$ & 378 & A 1064 & 0.29 & 71.16 \\
\hline Rugby ppm 8 & 27 & $1(1)$ & 150 & A 888 & 0.21 & 79.24 \\
\hline Enzone ppm6 & 28 & $1(1)$ & 78 & A 2136 & 0.44 & 55.79 \\
\hline Enzone ppm8 & 36 & $2(1)$ & 217 & A 2264 & 0.49 & 50.38 \\
\hline
\end{tabular}

Table 2: The effect of different nematicides on control of olive root-knot M. javanica on old olive seedling varieties Dezfuli.

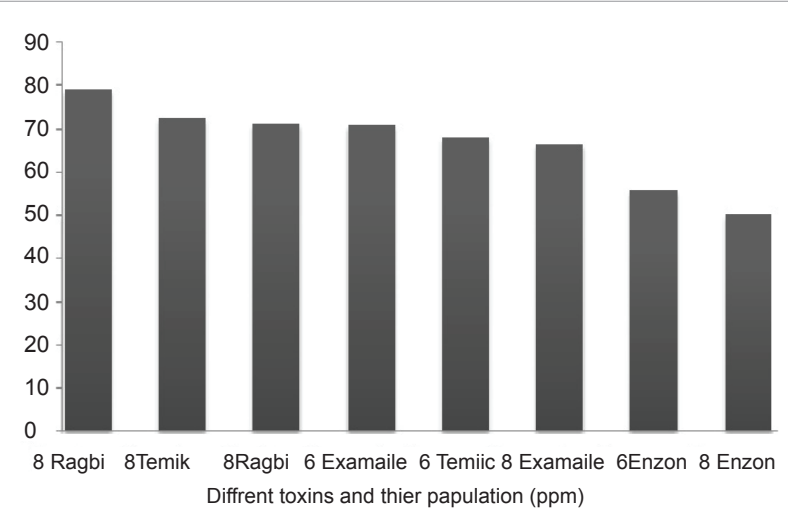

Figure 1: The effects of different pesticides on olive root-knot Meloidogyne javanica.

reduction of 79/24) followed by Temik, Oxamyl, and Enzone. All tested toxins reduced the population of nematode from $50 \%$ (Enzone toxin) to $80 \%$ (Rugby) (Figure 1 ).

Adding Rugby toxin one week after inoculation of plant by Nematode egg and larvae caused a significant decrease in the number of egg and larvae of roots and population of larvae in soil; this decrease has had a direct relationship with the increase of toxin concentration. Higher concentration of toxin had a better effect in Temik toxin that seems reasonable considering the fact that with increasing concentration of toxin, its rate in the soil becomes further which results in the better effectiveness. In the case of Oxamyl toxin, its lower concentration showed a better effect.

For Enzone toxin which was tested on the root-knot nematode of olive for the first time, the results showed that the concentration of $6 \mathrm{ppm}$ of the toxin and its application one week after inoculation of plant with nematode's second instar larvae had a better effect than its higher concentration. According to the results of the research, this toxin had a less effect in reducing nematode population than the other applied toxins. But, because it was the first time to evaluate this toxin, repeating this experiment by both the other concentrations of the toxin and its application concurrently with inoculation of egg and the second instar larvae of the nematode seems necessary. The research showed that using the toxin of liquid Rugby can be considerably effective in reducing nematode population in the soil; regarding the point that granular Temik toxin is more used in Khouzestan's greenhouses and using granular toxins is difficult for farmers, using liquid toxin of Rugby which is applied easily and together with irritation water can be offered to the farmers. Based on the results of the research, all the studied toxins had a positive impact on the control of this nematode resulted in the reduction of nematode population between 50 to 80 percent.

In Hoseininejad's experiment, it was shown that the most effective nematicide was Temik and the toxins, Oxamyl, Nemacur, Rugby, and Mucap were placed in the next categories. In addition, according to this researcher, Lamberti and Di Vito stated that disinfection of olive seedling infected by root-knot nematode with Aldicarb and Motomyl has significantly reduced the nematode population without adverse effects on plants while Carbofuran has cause phytotoxicity and Nemacur has reduced plant growth [11]. In the experiment of Acosta and colleagues, on chemical control of $M$. incognita, was also shown that the higher concentrations of the toxins, Fenamiphos and Oxamyl, had the maximum reduction in egg and larvae of nematode population [16].

\section{References}

1. Meschi M, Khazini F, Esmati A, Shirzad H, Zarrabi MM (2002) Olive Guide (Planting, Harvesting, Processing). Publication of Agricultural Education. 193 pp.

2. http://www.Faostat.fao.org

3. Anonymous (2008) Statistical Yearbook of Khouzestan's Agriculture in 1386-87. Agricultural Organization of Khouzestan, Project Management and Planning, Office of Statistics and Programming.

4. Sasanelli N (2009) Olive nematodes and their control. Integrated management of fruit crops and forest nematodes. Springer science+ Business Media B.V. $346 \mathrm{pp}$.

5. Nico Al, Jiménez-Díaz RM, Castillo $P(2003)$ Host suitability of the olive cultivars arbequina and picual for plant-parasitic nematodes. J Nematol 35: 29-34.

6. Nicol Al, Rapoport HF, Jiménez-Diaz RM, Castillo P (2002) Incidence and population density of plant-parasitic nematodes associated with olive planting stocks at nurseries in Southern Spain. Plant Diseases 86: 1075-1079.

7. Barouti SH, Holami G (1995) Plant Nematology of Iran Up to 1365. Plant Pests and Diseases Research Institute. Iran.

8. Hoseninejad A, Tanha-Maafi Z, Baroti S (1998) Nematodes of olive tree (Olea europea) in Iran. Journal of Plant Diseases 65: 46-54.

9. Mahdikhani Moghadam A, Kheiri A, Mohammadi M, Eshtiagh H, Okhovat M (2003) The Introduction of Three New Species of the Genus, Meloidogyne, for Iran. Journal of Plant Disease 39: 189-211.

10. Shawky S M, El-Sawi M A M, Nabil Y M (2004) Effect of some nematicides on controlling root knot nematodes and determine their residues in olive fruits and soil. Annual Agricaltural Science Cair 49: 389-399.

11. Hoseninejad A (1999) The Final Report of the Research Project of Studying 
Citation: Soltani T, Nejad RF, Ahmadi AR, Fayazi F (2013) Chemical control of Root-Knot Nematode (Meloidogyne javanica) On Olive in the Greenhouse conditions. J Plant Pathol Microb 4: 183 doi:10.4172/2157-7471.1000183

the Possibility of Controlling Root-Knot Nematode of Olive by Non-Fumigatory Nematicide Toxins. Plant Research Institute of Iran.

12. Rostami M, Hoseininejad A, Hoseinipour A (2004) The Impact of Chemical Toxins on the Root-Knot Nematodes of Cucumber Cultivation in Greenhouse in the Province, Kerman. Abstracts of the Sixteenth Plant Congress in Iran 2: 253.

13. Naseby DC, Pascual JA, Lynch JM (2000) Effect of biocontrol strains of Trichoderma on plant growth, Pythium ultimum polulations, soil microbial communities and soil enzyme activities. J Appl Microbiol 88: 161-169.
14. McClure MA, Kruk TH, Misaghi I (1973) A method for obtaining quantities of clean meloidogyne eggs. J Nematol 5: 230.

15. Jenkins WR (1964) A rapid centrifugal flotation technique for separating nematodes from soil. Plant Diseses Report 48: 692.

16. Acosta N, Vicente N, Abreu E, Medina-Gaud S (1987) Chemical control of Meloidogyne incognita, Rotylenchulus reniformis and Anthonomus eugenii in Capsicum annuum and C.frutescens. Nematropica 17: 163-168. 